\title{
A COOPTAÇÃO SINDICAL CORPORATIVISTA E A LEGALIZAÇÃO DA CLASSE TRABALHADORA BRASILEIRA
}

\section{Bruno Ferraz Hazan* \\ Luciana Costa Poli*}

RESUMO: O presente trabalho apresenta uma análise da política corporativista de Getúlio Vargas e dos elementos a ela agregada que culminaram com a consolidação do mito de outorga e da perda de identidade da classe trabalhadora brasileira. De início, serão investigadas as primeiras manifestações do sindicalismo no Brasil, a fim de se demonstrar que o Direito do Trabalho no país não pode ser totalmente proclamado como dádiva estatal. Em sequência, os elementos da política corporativista serão examinados, assim como sua correlação com a desconexão normativa e sindical e com a perda de identidade sentidas pela classe trabalhadora.

Palavras-chave: Sindicalismo. Identidade de classe. Mito da outorga. Corporativismo.

\section{UNION CO-OPTATION BY CORPORATISM AND LEGALIZATION OF THE BRAZILIAN WORKING CLASS}

\begin{abstract}
This paper presents an analysis of Getulio Vargas' corporative politic and the elements added to it that culminated in the consolidation of the granting myth and the loss of identity of the Brazilian working class. Initially, the first manifestations of labor movement in Brazil will be investigated in order to demonstrate that the Labor Law in the country can not be fully proclaimed as state gift. In sequence, the elements of corporatism will be examined as well as their correlation with the normative and union disconnection and with the loss of identity felt by the working class.
\end{abstract}

Keywords: Sindicalism. Class identity. Granting myth. Corporatism.

\section{INTRODUÇÃO}

O estudo da evolução histórica do Direito do Trabalho no Brasil, não obstante as inúmeras divisões doutrinárias possíveis, é geralmente concentrado em três grandes blocos: o primeiro, a partir da abolição da escravatura; o segundo, a partir da ascensão de Getúlio Vargas no poder; e o terceiro, a partir da promulgação da Constituição de 1988. É comum

Bruno Ferraz Hazan. Doutor em Direito Privado e Mestre em Direito do Trabalho pela Pontifícia Universidade Católica de Minas Gerais. Professor na Escola Superior Dom Helder Câmara/MG. E-mail: bruno.hazan@gmail.com.

Luciana Costa Poli. Pós-Doutora pela UNESP (Bolsista da CAPES/PNPD). Doutora em Direito Privado pela Pontifícia Universidade Católica de Minas Gerais. Mestra em Direito e Instituições Políticas pela Universidade FUMEC/MG. Professora na Pontifícia Universidade Católica de Minas Gerais/MG. E-mail: lucostapoli@yahoo.com.br. 
perceber, por outro lado, que existe um conformismo doutrinário quanto à importância de cada fase. Costuma-se, assim, subjugar a primeira em detrimento às demais, em especial diante da intensa produção legislativa da década de 1930.

Esse visível apego à legislação heterônoma estatal acaba ocultando a significativa ação coletiva e sindical dos trabalhadores a partir de meados do século XIX e, principalmente, no início do século XX. Como consequência, instituiu-se uma narrativa pautada na consolidação de um Direito do Trabalho como dádiva estatal e desvinculada de qualquer manifestação autônoma da classe trabalhadora.

Não se nega que as décadas de 1930 e 1940 foram significativas - e ardilosas, como se pretende mostrar -, porém reduzir a consolidação do ramo trabalhista à benesse estatal constitui descomunal injustiça à classe trabalhadora.

O presente trabalho, nessa perspectiva, pretende investigar como o discurso consolidado a partir da década de 1930, em especial por meio da política do corporativismo de cooptação das organizações sindicais, desconectou os trabalhadores dos centros do poder, impulsionando-os não apenas ao mito da outorga estatal, mas à perda da própria identidade e orientação como classe.

\section{AS PRIMEIRAS MANIFESTAÇÕES DO SINDICALISMO NO BRASIL}

Diferentemente do que se assistiu em outros países (especialmente nos europeus, mas também em alguns do continente americano), as relações trabalhistas brasileiras foram estruturadas a partir de um modelo colonial de longo prazo, prevalecente até pelo menos o início do século XIX. Fausto (2006, p. 47) explica que "como aconteceu em toda a América Latina, o Brasil viria a ser uma colônia cujo sentido básico seria o de fornecer ao comércio europeu gêneros alimentícios ou minérios de grande importância.”

Durante o período colonial, a escravidão foi a principal forma de apropriação do trabalho - a exploração do trabalho livre era raramente vista (FAUSTO, 2006, p. 47). Como a existência do Direto do Trabalho e a evolução dos seus institutos pressupõem a liberdade na prestação dos serviços, qualquer debate relevante atinente ao ramo juslaboral no Brasil só foi possível depois da abolição da escravatura, com a Lei Áurea (1888). 
Os primeiros movimentos grevistas mais expressivos, eclodidos no campo (a economia brasileira era essencialmente agrícola), foram então registrados a partir de $1888^{1} \mathrm{e}$ até 1930 (FAUSTO, 2006, p. 283-284). E isso apesar de a República brasileira, por inspiração do liberalismo político e econômico, até então não ter cuidado de regulamentar ou mencionar o trabalho humano em seus textos legislativos ${ }^{2}$.

De fato, a incorporação e o reconhecimento da classe trabalhadora era mais do que uma questão meramente econômica. A solução exigia a "reelaboração dos laços morais que amarravam o conjunto social, sem reverter a ordem", ou seja, tratava-se de uma saída "de desenvolvimento conservador da estrutura social[...] garantida pela inclusão do proletariado na sociedade, permitindo-lhe participar dela econômica e moralmente sem romper, contudo, os limites da classe social, impostos e assegurados pelo Estado ditatorial”. (SUPERTI, 2004, p. 115-116)

Desenvolve-se, a partir disso, um ideário anarquista de "ataque violento a ordem material pela destruição das instituições", absorvido pelo proletariado em face do "abandono a que foi submetida a classe do trabalho" (SUPERTI, 2004, p. 124). Exatamente por isso o Estado assumiu "uma postura repressiva diante das manifestações operárias", sendo que a violência se tornou "um meio eficaz de manutenção das relações sociais de dominação ao longo da primeira república”. (SUPERTI, 2004, p. 125)

Realmente, embora a Constituição de 1891 tenha previsto o direito de associação em seu artigo 72, §8 , só no ano de 1920 o Supremo Tribunal Federal (STF) entendeu que referido dispositivo alcançava os direitos de sindicalização e de greve (SÜSSEKIND, 2003, p. 1111. v. 2). Em razão disso, até a segunda década do século XX, houve intensa repressão aos movimentos sociais e às primeiras organizações de trabalhadores no Brasil.

Isso, no entanto, não impediu a deflagração de alguns movimentos importantes já no início do século XX. As condições de trabalho precárias e a superexploração da mão de obra decorrentes do liberalismo jurídico, somadas a uma intensa crise econômica vinculada à política econômica liberal, foram circunstâncias consideráveis para o surgimento de

\footnotetext{
${ }^{1}$ Vale ressalvar que alguns movimentos pontuais já haviam despontado ainda na metade do século XIX. "Uma das primeiras lutas organizadas, realizada no Rio, foi em 1858, quando os tipógrafos dos jornais Diário do Rio de Janeiro, Correio Mercantil e Jornal do Comércio, insatisfeitos com os míseros salários que percebiam, declararam-se em greve, exigindo uma elevação de 10 tostões diários em seus vencimentos”. (TELLES, 1981, p. 2-3)

${ }^{2}$ Ressalva-se a garantia de livre exercício de profissões prevista no artigo $72, \S 4^{\circ}$, da Constituição de 1891 , firmada, na verdade, na concepção da soberania da vontade individual. (SÜSSEKIND, 2003, p. 72. v. 1)
} 
organizações sindicais - único espaço de integração e socialização de trabalhadores na época. (SILVA, 2008, p. 131) ${ }^{3}$

Mais uma vez destoando dos países de capitalismo avançado, o Brasil não teve a industrialização como fator determinante para o reconhecimento formal da classe trabalhadora - e o sindicalismo pátrio foi exemplo disso, pois as primeiras associações de classe formalmente reconhecidas foram rurais. Na passagem do século XIX para o século XX, o Decreto n. 979 de 1903 autorizou a criação de sindicatos agrícolas, e, como não havia nenhuma referência à interferência estatal nas organizações, a sindicalização era, de certa forma, pautadaem aspectos de liberdade ${ }^{4}$.

Os sindicatos surgidos, então, eram independentes do Estado - apesar de a lei ter regulamentado alguns dos seus aspectos estruturais, eles eram livres e autônomos e não respondiam a nenhum órgão governamental. Uma curiosidade é que tinham constituição mista, ou seja, tanto os trabalhadores quanto os patrões poderiam ser sócios dos sindicatos ${ }^{5}$, o que se percebe pela redação do do Decreto n. 6.532 de $1907^{6}$, que regulamentou o Decreto anterior.

Também em 1907, por meio do Decreto n. 1.637, o direito de sindicalização foi estendido aos profissionais liberais e aos trabalhadores urbanos de qualquer profissão. Contudo, apesar da legalização da organização sindical, o país, na realidade fática, ainda tratava os movimentos sociais como questão de polícia (AQUINO, 2000, p. 182). Some-se a

\footnotetext{
${ }^{3}$ A mesma autora apresenta alguns exemplos dessa crescente conflituosidade: a parede dos chapeleiros de 1896, uma das primeiras greves operárias registradas na história brasileira; a paralisação dos tecelões em São Paulo em 1901; a greve dos cocheiros e dos têxteis no Rio de Janeiro em 1903; e, ainda, greves gerais em 1905 (Santos) e 1907 (São Paulo). (SILVA, 2008, p. 131)

${ }^{4} \mathrm{O}$ que pode ser percebido, por exemplo, nos artigos $1^{\circ}, 2^{\circ}, 7^{\circ}$ e 11 do referido Decreto: “Art. $1^{\circ}$ É facultado aos profissionais da agricultura e industrias ruraes de qualquer genero organizarem entre si syndicatos para o estudo, custeio e defesa dos seus interesses. Art. $2^{\circ} \mathrm{A}$ organização desses syndicatos é livre de quaesquer restrições ou onus, bastando, para obterem os favores da lei, depositar no cartorio do Registro de hipothecas do districto respectivo, com a assignatura e rosponsabilidade dos administradores, dous exemplares dos estatutos, da acta, da installação e da lista dos socios, devendo o escrivão do Registro enviar duplicatas á Associação Commercial do Estado em que se organisarem os syndicatos. [...] Art. $7^{\circ} \mathrm{A}$ dissolução do syndicato só poderá ser declarada pela unanimidade dos socios ou quando seu numero fique reduzido a menos de sete por um prazo superior a quinze dias. [...] Art. 11 É permittida aos syndicatos a formação de uniões, ou syndicatoscentraes com personalidade juridica separada podendo abranger syndicatos de diversas circumscripções territoriais". (BRASIL, 8 jan. 1903).

${ }_{5}^{5}$ A realidade, porém, não comportou esse tipo de sindicato, pois os empregadores acabaram sendo os únicos beneficiados pelo "paritarismo" estabelecido.

6 "Art. $4^{\circ}$ Consideram-se profissionais para todos os efeitos da lei: O proprietário, o cultivador, o arrendatário, o parceiro, o criador de gado, o jornaleiro, e quaesquer pessoas empregadas em serviço dos prédios rural, bem como a pessoa jurídica cuja existência tenha por fim a exploração da agricultura ou outra industria rural". (BRASIL, 5 fev. 1908)
} 
isso o fato de que a classe trabalhadora brasileira, sem uma base intelectual que the assegurasse a capacidade para reivindicar e lutar por direitos, ainda não possuía tradição de organização ${ }^{7}$ :

\begin{abstract}
Muito embora tais Decretos tenham consentido as reuniões entre trabalhadores com objetivo de promover a luta por seus direitos laborais, poucos foram os benefícios alcancados naquele período, em decorrência da ausência de uma cultura sindical, o que os levava a não reinvindicarem melhorias nas condições de trabalho. (EÇA; LOBATO, 2015, p. 135)
\end{abstract}

A estrutura das entidades sindicais mostrava-se vulnerável, e elas não tinham atuação articulada. Os trabalhadores eramsubjugados não só pelo Estado, mas pelos senhores da terra e pelos recém-surgidos capitalistas. Definitivamente, a ação sindical, na época, não foi suficiente para que o Estado se visse obrigado a reconhecer e a generalizar direitos laborais.

Independentemente da postura do Estado (ainda balizado pelo ideário liberal), movimentos trabalhistas se desenvolveram à margem da lei, especialmente em razão da crescente industrialização, que começou a entabular condições precárias ao proletariado brasileiro: “desemprego, inflação, e baixos salários contribuíram para mobilizar a classe operária, liderada sobretudo pelos anarquistas.” (AQUINO, 2000, p. 183)

O projeto de desenvolvimento do país trouxe consigo a necessidade de mão de obra especializada. Muitos imigrantes, na sua maioria italianos e espanhóis, chegaram ao Brasil trazendo consigo não só a experiência no trabalho fabril, mas também a tradição europeia de organização sindical, o que levou à formação de um pensamento voltado à proteção dos que viviam do trabalho. Tiveram início as grandes lutas operárias, com a nova composição da classe trabalhadora ${ }^{8}$.

A partir de 1917 (especialmente em razão da crise decorrente da Primeira Guerra Mundial e, ainda, da onda revolucionária socialista que passava pela Europa) uma série de grandes greves foi deflagrada no Brasil. A primeira delas, irrompida por motivos de jornada

\footnotetext{
${ }^{7}$ Apesar da falta de conhecimento, de tradição e toda a oposição à organização sindical feita pelos empresários e pelo Estado, é bom mencionar que a partir de 1906 começaram a surgir organizações nas cidades mais industrializadas. Foi o caso da Federação Operária Regional, no Rio de Janeiro, que realizou seu primeiro congresso naquele ano e orientou a classe trabalhadora a fundar sindicatos, uniões e resistências. (SÜSSEKIND, 2003, p. 1094. v. 2)

${ }^{8}$ Justamente por isso, já em 1907 foi editado o Decreto n. 1.641 para a expulsão dos imigrantes: "a ordem de expulsão dos imigrantes - além das prisões de militantes, invasão das entidades, etc. - consistirá na técnica legislativa repressiva por excelência, nessa I República, dirigida a sufocar a militância sindical de mão-de-obra fortemente migrante". (SILVA, 2008, p. 132)
} 
de trabalho e reajuste salarial no paulista Cotonifício Crespi em 1917, é considerada por muitos como o marco inicial da fase de luta dos trabalhadores por melhores condições de trabalho (o movimento alastrou-se até o Rio de Janeiro, envolvendo mais de 50 mil operários cariocas). (SILVA, 2008, p. 135)

Essa importante onda de greves permitiu o resgate da questão social - quase esquecida - no bojo do Estado, coincidindo com a assinatura, pelo Brasil, do Tratado de Versailles, que instituía o compromisso estatal de intervenção nas relações de trabalho. (SILVA, 2008, p. 136)

Não obstante, a intervenção estatal prosseguia majoritariamente com o aspecto repressivo. Os movimentos grevistas acabaram, portanto, implicando uma maior contenção da classe trabalhadora pelo Estado. Exemplos disso foram o Decreto n. 4.269 de 1921 (que permitia o fechamento provisório de associações que incorressem em atos nocivos à ordem pública); o Decreto n. 4.247 de 1921 (que determinava a expulsão dos estrangeiros com condutas nocivas à ordem pública); e o Decreto n. 5.221 de 1927 (que determinava o fechamento de associações que praticassem atos contrários à ordem, à moralidade e à segurança públicas e tornava inafiançável o "crime" de provocar cessação ou suspensão de trabalho). (SILVA, 2008, p. 138)

A repressão estatal, por outro lado, não afastou a importância dos movimentos sindicais para a mudança da postura do Estado em relação aos direitos dos trabalhadores. Até mesmo a edição de um Código de Trabalho foi cogitada na época, mas, no plano fático, apenas leis esparsas de proteção ao trabalho foram aprovadas. Houve, por exemplo, a criação do Departamento Nacional do Trabalho (em 1918, mas efetivada em 1923); a regulamentação de obrigações decorrentes de acidente do trabalho (em 1919); a criação de Caixas de Aposentadorias e Pensões (em 1923), culminando com o estabelecimento de um sistema de estabilidade no emprego (em 1928); a regulamentação do direito de férias (em 1926); e a revisão constitucional que atribuiu à União a competência para legislar sobre matéria trabalhista (em 1926). (SILVA, 2008, p. 138)

\section{O MODELO CORPORATIVO INSTITUÍDO POR GETÚLIO VARGAS}


Somente a partir da terceira década do século XX, no Governo Provisório instalado após a Revolução de 1930, é que o Brasil começou a produzir com mais intensidade textos legislativos sobre proteção do trabalho. A década de 1930, em verdade, inaugurou uma nova fase para o Brasil com a chegada de Getúlio Vargas ao poder?.

A crise econômica mundial de 1929 favoreceu a vitória do "movimento revolucionário", que culminou com a ascensão de Getúlio Vargas ao governo. A superação da crise exigia uma reorganização significativa dos mercados de trabalho e capital, com o abandono da economia liberal e o favorecimento da regulação estatal das forças dinâmicas da economia. Visualizou-se, assim, a necessidade de disciplinar os elementos preponderantes do fenômeno de produção - o capital e o trabalho:

\begin{abstract}
Examinando detidamente o fator de maior predominância na evolução social, penso não errar afirmando que a causa principal de falharem todos os sistemas econômicos experimentados para estabelecer o equilíbrio das forças produtoras se encontra na livre atividade permitida à atuação das energias naturais, isto é, na falta de organização do capital e do trabalho [...]. (VARGAS, 1938, p. 117, v. 1)
\end{abstract}

A partir desse momento, o Estado concentrou esforços na tentativa de superar as características que ainda marcavam sua estrutura econômica, social e política. De fato, estavase diante de uma sociedade essencialmente agrária; sem um operariado urbano organizado; com resquícios de uma ordem escravocrata e patriarcal; atrelada a um modelo econômico eminentemente exportador e a uma política sob o domínio do eixo Minas/São Paulo. (BIAVASCHI, 2007, p. 88)

Como parte da política de industrialização arquitetada por Getúlio Vargas e sua equipe, a normatização heterônoma trabalhista decorreu da grande interferência do Estado no mundo do trabalho. A coordenação do processo pela via estatal foi concebida como alternativa à sociedade brasileira em luta pela modernização. (BIAVASCHI, 2007, p. 196)

A intervenção na economia passa a ser, portanto, um elemento central da política de Estado a partir da década de 1930. A proposta era disciplinar o capital para controlar o

\footnotetext{
${ }^{9}$ A questão social já fazia parte dos debates políticos desde a década de 1920 , quando foram desencadeados os primeiros movimentos operários mais significativos e quando foram iniciadas (mas não consolidadas) as primeiras ações governamentais em favor da industrialização. O que diferiu a política da década de 1930 foi a abrangência dada à legislação trabalhista, permitindo articular trabalho e capital numa proposta de cooptação por parte do Estado que, assim, passaria a ser o mediador, o executor, o legislador e o julgador dos conflitos sociais. (SUPERTI, 2004, p. 197-198).
} 
trabalho em prol do mercado interno e da industrialização (SUPERTI, 2004, p. 192-193): “envolto pelas concepções castilhista-positivista, Vargas articula a montagem de um poder público centralizado, altamente intervencionista, burocratizado e industrializante" (SUPERTI, 2004, p. 196). Assim, a legislação trabalhista de cooptação da classe trabalhadora foi consequência dessa política econômica:

Com a instauração do governo provisório, Vargas ressaltava a necessidade de se "disciplinar as forças dinâmicas do mercado", o que incluía a regulamentação do mundo do trabalho. A fórmula comtiana de "incorporação do proletariado à sociedade moderna" virou o clichê das soluções apresentadas pelo governo às relações capital-trabalho. (SUPERTI, 2004, p. 197)

Naquele momento, portanto, em decorrência da industrialização, com a oferta de empregos nas grandes cidades, ocorreu uma incorporação de grande massa de trabalhadores à indústria. O desenvolvimento industrial, ao permitir a intensificação das atividades sindicais, instigou uma política estatal de minucioso controle dos movimentos operários o que, decerto, obstou o avanço das lutas por melhores condições de trabalho (EÇA; LOBATO, 2015, p. 136):

O caráter retardatário da formação do capitalismo no Brasil [...] implicou também a
contenção dos salários dos trabalhadores industriais. Para garanti-la, tornava-se
necessária, na perspectiva do getulismo, a interdição da ação operária autônoma. Tal
papel caberia à estrutura sindical, tal como foi montada no Brasil. Com sua
imposição, buscava-se criar um hiato entre as duas gerações do movimento operário,
que no Estado Novo é submetido à passividade e/ou à participação tutelada. (LOBO,
2009, p. 114)

Ademais, a intencional supressão estatal dos conflitos entre as classes, a fim de substituí-los pela cooperação, facilitou a execução da política de industrialização (pautada no suposto consenso entre as camadas sociais). (LOBO, 2009, p. 114)

Getúlio Vargas, vislumbrando, então, uma conjuntura mais favorável (menor politização do operariado), tão logo assumiu o governo criou o Ministério do Trabalho (Decreto n. 18.433, de 1930), com o intuito de harmonizar o desajuste entre os elementos representativos do trabalho e do capital. Em março do ano seguinte, foi assinado o Decreto $\mathrm{n}$. 19.770 (Lei de Sindicalização), primeiro diploma legal a disciplinar a estrutura sindical, atrelando os sindicatos ao Ministério do Trabalho. 
Como o sistema sindical brasileiro começou a tomar forma apenas a partir do Estado Novo e do seu dirigismo (com destaque para o Decreto n. 19.770 de 1931), pode-se afirmar que essa fase "marcou o início da nossa verdadeira organização sindical". (SÜSSEKIND, 2003, p. 1095. v. 2)

Além de detalhar minuciosamente a estrutura e a organização dos sindicatos, proibindo sua vinculação a ideologias religiosas, políticas ou sociais - neutralidade sindical (artigo 1", alínea “f”), o Decreto n. 19.770 consagrou a divisão por categorias (artigo $1^{\circ}$, caput), a investidura sindical pelo depósito de estatutos no Ministério do Trabalho (artigo $2^{\circ}$ ), a estrutura confederativa formada por federações e confederações (artigo $3^{\circ}$ ) e a unicidade sindical (artigo $9^{\circ}$ ). O texto também regulamentou a negociação coletiva, vinculando sua validade à ratificação pelo Ministério do Trabalho (artigos $7^{\circ}$ e 10 ), e vetou a sindicalização de servidores públicos e empregados domésticos (artigo 11, parágrafo único). Curiosamente, foi reconhecida a natureza antissindical das condutas de rebaixar, dispensar ou suspender o trabalhador por motivo de associação sindical (artigo 13) ${ }^{10}$.

10 “Art. $1^{\text {o }}$ Terão os seus direitos e deveres regulados pelo presente decreto, podendo defender, perante o Governo da República e por intermédio do Ministério do Trabalho, Indústria e Comércio, os seus interesses de ordem econômica, jurídica, higiênica e cultural, todas as classes patronais e operárias, que, no território nacional, exercerem profissões idênticas, similares ou conexas, e que se organizarem em sindicados, independentes entre si, mas subordinada a sua constituição às seguintes condições [...] f) abstenção, no seio das organizações sindicais, de toda e qualquer propaganda de ideologias sectárias, de caráter social, político ou religioso, bem como de candidaturas a cargos eletivos, estranhos à natureza e finalidade das associações. [...] Art. $2^{\circ}$ Constituídos os sindicatos de acordo com o artigo $1^{\circ}$, exige-se ainda, para serem reconhecidos pelo Ministério do Trabalho, Indústria e Comércio, e que adquirirem, assim, personalidade jurídica, tenham aprovados pelo Ministério os seus estatutos, acompanhados de cópia autêntica da ata de instalação e de uma relação do número de sócios com os respectivos nomes, profissão, idade, estado civil, nacionalidade, residência e lugares ou empresas onde exercerem a sua atividade profissional. [...] Art. $3^{\circ}$ Poderão os sindicatos, em número nunca inferior a três, formar no Distrito Federal em cada Estado, e no Território do Acre, uma federação regional, com sede nas capitais, e, quando se organizarem, pelo menos, cinco federações regionais, poderão elas formar uma confederação, com sede na capital da República. Denominar-se-á - Confederação Brasileira do Trabalho - a que se constituir por federações operárias e - Confederação Nacional da Indústria e Comércio - a que se constituir por federações patronais. [...] Art. $7^{\circ}$ Como pessoas jurídicas, assiste aos sindicatos a faculdade de firmarem ou sancionarem convenções ou contratos de trabalho dos seus associados, com outros sindicatos profissionais, com empresas e patrões, nos termos da legislação, que, a respeito, for decretada. [...] Art. $9^{\circ}$ Cindida uma classe e associada em dois ou mais sindicatos, será reconhecido o que reunir dois terços da mesma classe, e, se isto não se verificar, o que reunir maior número de associados. [...] Art. 10 Além do que dispõe o art. $7^{\circ}$, é facultado aos sindicatos de patrões, de empregados e de operários celebrar, entre si, acordos e convenções para defesa e garantia do interesses recíprocos, devendo ser tais acordos e convenções, antes de sua execução, ratificados pelo Ministério do Trabalho, Indústria e Comércio. [...] Art. 11 [...] Parágrafo único. Não entraram na classe de empregados: a) os empregados ou funcionários públicos, para os quais, em virtude da natureza de suas funções, subordinadas a princípios de hierarquia administrativa, decretará o Governo um estatuto legal; b) os que prestam serviços domésticos, o qual obedecerá a regulamentação à parte. [...] Art. 13. É vedada aos patrões ou empresas despedir, suspender e rebaixar de categoria, de salário ou de ordenado o operário ou empregado, pelo fato de associar-se ao sindicato de sua classe, ou por ter, no seio do mesmo 
O Decreto n. 19.770 de 1931 foi elaborado dentro da perspectiva de prevenção e solução de conflitos, já que os sindicatos eram considerados essenciais para o estabelecimento da cooperação social. Negava-se o conflito entre capital e trabalho, na tentativa de apagar o papel do sindicalismo no desenvolvimento social e trabalhista e de se obter uma espécie de pacto de colaboração entre os sindicatos e o Estado. Nesse sentido, discursou Getúlio Vargas em 4 de maio de 1931, meses após a publicação do Decreto:

\begin{abstract}
O que parece urgente, sem dúvida, é a necessidade de revisão, no quadro dos valores sociais, a fim de que, modificada a sua estrutura íntima, se torne possível o equilíbrio econômico, cuja ruptura constitui perigo iminente para a civilização. Para levar a efeito essa revisão, faz-se mister congregar toda as classes, em uma colaboração efetiva e inteligente [...]. Tão alevantado propósito será atingido quando encontrarmos, reunidos numa mesma assembleia, plutocratas e proletários, patrões e sindicalistas, todos os representantes das corporações de classe, integrados, assim, no organismo político do Estado. [...] As leis, há pouco decretadas, reconhecendo essas organizações [sindicais], tiveram em vista, principalmente seu aspecto jurídico, para que, em vez de atuarem como força negativa, hostis ao poder público, se tornassem, na vida social, elemento proveitoso de cooperação [...] do Estado. (ROMITA, 2001, p. 54)
\end{abstract}

É notória a estrutura corporativista implantada por Getúlio Vargas, com o nítido foco de promover o controle e a cooptação, pelo Estado, das organizações sindicais. São características do corporativismo: sindicatos reconhecidos como pessoas jurídicas de direito público; funções delegadas ao poder público por parte do sindicato reconhecido pelo Estado; vigilância estatal sobre as associações reconhecidas; limitações legais à autonomia sindical; e criminalização dos movimentos grevistas. (MAZZONI apud SILVA, 2008, p. 53) ${ }^{11}$

Em 1934, foi publicado o Decreto n. 24.694, que manteve a estrutura até então consagrada - intervencionismo estatal e cooperação nacional -, inclusive com previsão de fechamento de sindicatos e de intensa fiscalização por parte do Ministério do Trabalho. Ocorre que, logo em seguida, foi promulgada a Constituição de 1934, fixando a possibilidade

sindicato, manifestado ideias ou assumido atitudes em divergência com os seus patrões". (BRASIL, 29 mar. 1931)

${ }^{11}$ Importa frisar que o denominado corporativismo se desenvolveu especialmente na década de 1930, não só no Brasil, mas em diversos países, como consequência e reposta ao capitalismo industrial que surgia: "no intuito de contornar a instabilidade e a crescente diferenciação social inerentes às mudanças econômicas então em curso, o corporativismo mostrou-se uma solução [...] dedicou-se sobretudo à promoção da solidariedade social entre os grupos profissionais e os patronais emergentes nesse cenário, por meio tanto da concessão de direitos trabalhistas e previdenciários como pelo controle político da organização coletiva dessas mesmas categorias". (QUINALHA, 2012, p. 329) 
da pluralidade sindical, condicionada à regulamentação por norma infraconstitucional (artigo 120).

Em tese, seria possível a coexistência de sindicatos da mesma categoria na mesma base territorial, conforme previsão constitucional. Porém, como até então o Decreto n. 24.694 de 1934 era a norma infraconstitucional vigente, ficava inviável, na prática, a efetivação da estrutura pluralista autorizada pela Carta de 1934.

Não obstante a clara incompatibilidade do Decreto com a Constituição (o que nunca foi reconhecido pelo STF, diga-se de passagem), suas restrições macularam a adoção da pluralidade sindical. Um exemplo de restrição era o seu artigo $5^{\circ}$, inciso II, que exigia a filiação de pelo menos um terço dos trabalhadores da categoria na base territorial para a criação do sindicato (o que, portanto, permitia a coexistência de no máximo três sindicatos).

Em 1937, Getúlio Vargas implantou seu regime ditatorial e impôs uma nova Constituição ao país. O corporativismo acentuou-se ainda mais no Estado Novo (que persistiu até outubro de 1945), já que as novas perspectivas constitucionais e legais não romperam com o sistema - pelo contrário, intensificaram o controle sindical, como, por exemplo, por meio da vinculação da existência sindical ao reconhecimento pelo Estado e da retomada da unicidade sindical.

Além disso, a Constituição de 1937, "marcando sua tendência corporativista, instituiu o Conselho de Economia Nacional, cujos membros seriam indicados pelas entidades sindicais de empregadores e de trabalhadores [...] e teria o encargo de promover a organização corporativa da economia nacional". (SÜSSEKIND, 2001, p. 345-346) ${ }^{12}$

Nos anos de 1939 e 1940, sem desviar do curso corporativista implantado (ou seja, preservando a cooperação sindical com o Estado e a necessidade de reconhecimento formal pelo Ministério do Trabalho), foram publicados três Decretos-Lei: o n. 1.402, de 1939, o n.

\footnotetext{
${ }^{12}$ Eis o texto dos artigos 61 e 138 da Carta: "Art 61. São atribuições do Conselho da Economia Nacional: a) promover a organização corporativa da economia nacional; b) estabelecer normas relativas à assistência prestada pelas associações, sindicatos ou institutos; c) editar normas reguladoras dos contratos coletivos de trabalho entre os sindicatos da mesma categoria da produção ou entre associações representativas de duas ou mais categorias; [...] g) emitir parecer sobre todas as questões relativas à organização e reconhecimento de sindicatos ou associações profissionais; h) propor ao Governo a criação de corporação de categoria. [...] Art. 138. A associação profissional ou sindical é livre. Somente, porém, o sindicato regularmente reconhecido pelo Estado tem o direito de representação legal dos que participarem da categoria de produção para que foi constituído, e de defender-lhes os direitos perante o Estado e as outras associações profissionais, estipular contratos coletivos de trabalho obrigatórios para todos os seus associados, impor-lhes contribuições e exercer em relação a eles funções delegadas de Poder Público". (BRASIL. 10 nov. 1937)
} 
2.377, de 1940, e o n. 2.381, de 1940. Referidos Decretos-Lei consolidaram a estrutura hierárquica confederativa formada por sindicatos (base), federações e confederações (ápice), instituíram o imposto sindical e criaram um quadro de enquadramento sindical com revisões periódicas.

Constitui-se, assim, "a fase final e acabada do corporativismo, que se ensaiava implantar no país desde 1931" (MAGANO, 1993, p. 61. v. 3). Os mencionados Decretos-Lei, especialmente o último (que criou o sistema de enquadramento sindical), foram marcos da cooptação sindical, pois cessaram "definitivamente a liberdade para criação de entidades sindicais [...] a partir daí, somente poderem existir sindicatos se respaldados em categorias econômicas e profissionais previstas previamente no quadro mencionado." (COUTINHO, 2006, p. 277)

A intervenção estatal, portanto, viu-se reforçada no final da década de 30. Formalmente, estabeleceu-se a carta de reconhecimento sindical como novo padrão de controle, e, assim, a personalidade sindical (condição para exercício das prerrogativas sindicais) e toda a atividade sindical passaram a ser geridas e administradas pelo Ministério do Trabalho, em franca contradição com os preceitos da liberdade sindical.

A própria Exposição de Motivos do Anteprojeto que deu origem ao Decreto-Lei n. 1.402 de 1939 especificou que, naquele caso, o registro sindical realmente deveria servir para o controle e o atrelamento dos sindicatos ao Estado. Explica Romita (1985, p. 24), citando Oliveira Vianna:

\footnotetext{
'Com a instituição deste registro, toda a vida das associações profissionais passará a gravitar em torno do Ministério do Trabalho: nele nascerão; com ele crescerão; ao lado dele se desenvolverão; nele se extinguirão'. De fato, nesse regime 'o controle estatal é necessário e deve penetrar bem fundo na vida social destas associações; deriva logicamente da soma de poderes do Estado e das funções de ordem pública que lhes são conferidas pela nova Constituição' (Oliveira Vianna, Problemas de Direito Sindical, Max Limonad, Rio, 1943, pp. 209 e 115).
}

O modelo sindical brasileiro, então plenamente desenvolvido, foi inspirado no modelo italiano de $1926^{13}$, baseado na estrangulação dos conflitos e dos movimentos sociais,

13 Arnaldo Süssekind, um dos responsáveis pela elaboração da Consolidação das Leis do Trabalho (CLT), confirmou que o modelo de organização sindical brasileiro foi inspirado no italiano: "Afirma-se comumente que a Comissão da CLT se inspirou da Carta Del Lavoro. Tal acusação, além de confundir o todo com uma de suas partes, revela, sem dúvida, o desconhecimento da evolução das leis brasileiras sobre o Direito do Trabalho. Dos 
no protagonismo estatal na resolução dos conflitos coletivos e na necessidade de reconhecimento estatal das organizações sindicais. John D. French destaca:

\begin{abstract}
O infeliz destino dos trabalhadores brasileiros é fruto do fato de terem sido integrados, em organizações corporativas baseadas em código de trabalho copiado da legislação de Mussolini, visando ao controle dos sindicatos. Assim, o Estado brasileiro teria estabelecido um sistema de repressão aos trabalhadores baseado no modelo corporativo e fascista. (FRENCH, 2001, p. 31-32)
\end{abstract}

Em 1943, editou-se o Decreto-Lei n. 5.452, que aprovou a Consolidação das Leis do Trabalho (CLT). Apesar de terem sido solidificadas conquistas no plano dos direitos trabalhistas individuais, a CLT não promoveu alterações na seara coletiva ${ }^{14}$.

Coerente com a escolha interventiva e corporativa do governo brasileiro - mas em antítese à lógica da existência e da construção do sindicalismo nos países desenvolvidos (onde seu surgimento foi natural e espontâneo) - a normatização consolidada vinculou a existência sindical muito mais ao aval estatal do que à vontade da classe trabalhadora. Percebe-se, nesse cenário, que os direitos laborais individuais foram reconhecidos em troca do definhamento do Direito Coletivo do Trabalho.

\title{
4 A PERDA DA IDENTIDADE DE CLASSE COMO REFLEXO DO MODELO DE COOPTAÇÃO
}

O pensamento liberal (liberalismo) ganhou espaço no fim do século XVIII e início do século XIX, a partir da Revolução Francesa. Como teoria econômica, o liberalismo defendia a economia de mercado; como teoria política, defendia o que hoje se chama de Estado-Mínimo. (BOBBIO, 2002, p. 128)

Em nome dessa liberdade, inclusive de contratação, a Revolução Francesa (17891799) combateu e exterminou as corporações. A ideologia liberal conduzia os homens à regulação direta das relações de trabalho. Nesse cenário, os riscos aos quais os trabalhadores

onze títulos que compõem a Consolidação, apenas o V, relativo à organização sindical, corresponde ao sistema então vigente na Itália". (SÜSSEKIND, 2003, p. 62. v. 1.)

${ }^{14} \mathrm{Na}$ verdade, o Título V da CLT, que trata da Organização Sindical, foi totalmente consolidado dentro do paradigma corporativo. O $1^{\circ}$ capítulo (que regula a organização interna e externa do sindicato) decorre do Decreto-Lei n. 1.402, de 1939. O $2^{\circ}$ capítulo (que aborda o enquadramento sindical) decorre do Decreto-Lei $\mathrm{n}$. 2.381, de 1940. O $3^{\circ}$ capítulo (que trata da contribuição sindical) decorre dos Decretos-Lei n. 2.377, de 1940 e n. 4.298, de 1942.

Rev. de Direitos Sociais, Seguridade e Previdência Social| e-ISSN: 2525-9865| Maranhão

| v. 3 | n. 2 | p. 1 - 21 | Jul/Dez. 2017. 
estavam sujeitos no ambiente laboral eram assumidos por eles próprios, não pelos patrões, pela sociedade ou pelo Estado. A suposta liberdade, assim como a igualdade meramente formal, oprimia os trabalhadores.

A aparente distância que o Estado mantinha das relações privadas e sua posição omissa quanto à regulação da economia implicavam a sujeição da classe trabalhadora às determinações da capital ${ }^{15}$. A ideia de que seriam entregues à livre exploração do patrão fez com que os trabalhadores compreendessem que teriam de se unir para lutar (SÜSSEKIND, 2003, p. 1090. v. 2$)^{16}$.

A irresignação do indivíduo trabalhador, portanto, cedeu espaço às manifestações coletivas, que se revelaram mais eficientes: o capitalismo liberal iniciava a exposição dos seus efeitos deletérios sobre o mundo do trabalho, e normas autônomas de natureza laboral,

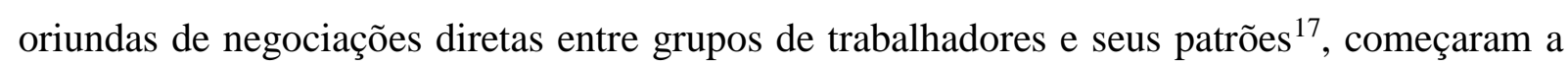
surgir como resposta, ainda que tímida, às reivindicações coletivas por melhores condições de trabalho e de vida. Os trabalhadores, organizados, iniciaram seu papel de atores e sujeitos do Direito Coletivo do Trabalho:

Todo esse processo desvelava a falácia da proposição jurídica individualista liberal enquanto modelo explicativo da relação empregatícia, eis que se referia a ambos os sujeitos da relação de emprego como seres individuais singelos. $\mathrm{Na}$ verdade, perceberam os trabalhadores que um dos sujeitos da relação de emprego, (o empregador) sempre foi um ser coletivo, isto é, um ser cuja vontade era hábil a detonar ações e repercussões de impacto social [...]. (DELGADO, 2016, p. 96)

Ao transcorrer do século XIX, com o reconhecimento do direito de associação sindical, eclodiram movimentos sindicais reivindicatórios pelo mundo. A partir disso, já no

\footnotetext{
${ }^{15} \mathrm{O}$ suposto distanciamento e a posição aqui mencionados dizem respeito ao aspecto econômico da locação de serviços decorrente do modelo baseado na livre iniciativa, na regulação privada e na livre concorrência. Não se confunde com neutralidade estatal - inexistente mesmo no ideário liberal -, já que todo o arcabouço legal para a manutenção e a propagação da suposta igualdade entre os contratantes (tomadores de serviço e prestadores de serviço) foi assegurado pelo próprio Estado (especialmente por legitimar o capitalismo). O contraponto aqui apresentado serve como referência para a compreensão da mudança de foco no paradigma do Estado Social modelo político-econômico em que o Estado, com a finalidade de corrigir os desequilíbrios do modelo liberal, assume um papel de intervenção direta no sistema econômico.

${ }^{16} \mathrm{O}$ mesmo autor destaca que "Entregue à sua fraqueza, abandonado pelo Estado, que o largava à sua própria sorte, apenas lhe afirmando que era livre, o operário não passava de um simples meio de produção." (SÜSSEKIND, 2003, p. 34. v. 1)

${ }^{17}$ As conquistas trabalhistas, coletivas e individuais, passaram a se efetivar por meio das associações sindicais dos trabalhadores em tratativas diretas com os patrões especialmente porque estes não conseguiam seguir com seu desenvolvimento produtivo sem o trabalho.
}

\section{Revista de Pesquisa e Educação Jurídica | e-ISSN: 2525-9636| Maranhão | v. 3 | n. 2 |} p. 1 - 21 | Jul/Dez. 2017. 
início século XX e em especial nos países centrais, o Estado (já transmutado em Estado Social) apoderou-se dos institutos e das conquistas sindicais, generalizando, pela via legal, normas básicas de proteção ao trabalho afastadas do ramo jurídico civilista e passando a reconhecer a legitimidade das associações de trabalhadores como instituições sociais.

Essa legitimação estatal do sindicalismo só foi possível em razão da ambivalência do "compromisso fordista para o proletariado ocidental". Assim, o proletariado perdeu sua identidade revolucionária em troca da perda de "sua negatividade de classe da sociedade civil" $(B I H R, 1998, \text { p. 38 })^{18}$. Isso se fez necessário ante a contradição histórico-política de um sindicalismo que surgiu naturalmente contestativo e foi apropriado como instituição reconhecidamente capitalista (social-democrata).

O proletariado viu, nesse compromisso, a "perspectiva de sair da miséria, da instabilidade, da incerteza, do futuro e da opressão desenfreada, que basicamente caracterizaram, até aquele momento, a condição proletária”. (BIHR, 1998, p. 39)

A história do Direito do Trabalho, portanto, se confunde com a história do sindicalismo, já que "o movimento sindical constituiu a primeira manifestação da dimensão coletiva daquele ramo do Direito e se mantém, até hoje, como uma das mais importantes manifestações da sua área regulativa colectiva.” (RAMALHO, 2015, p. 27)

É importante registrar que a normatização trabalhista heterônoma, apesar de ter sido impulsionada pela atuação reivindicatória e normativa autônoma das entidades sindicais, implicava (e até hoje implica) o controle do Estado capitalista sobre a classe trabalhadora por meio do direito. Tem-se, assim, que o surgimento do Direito do Trabalho - que acabou por materializar a legalização da classe operária ${ }^{19}$ - representou, ao mesmo tempo, uma vitória social expressiva e uma derrota política para os trabalhadores:

Claro, as condições de trabalho haviam melhorado; certamente, a classe operária vivia melhor, mas o preço a pagar havia sido o abandono de qualquer ambição revolucionária, de qualquer vontade de abater o capitalismo e de tomar para si os meios de produção. A oposição capital/trabalho havia se renovado numa aliança capital/trabalho, em compromisso. E o instrumento privilegiado desse comprometimento havia sido o direito. Ao se "legalizar" a "classe" operária, ela era capturada, neutralizada, amordaçada. (EDELMAN, 2016, p. 8)

\footnotetext{
${ }^{18} \mathrm{O}$ mesmo autor explica que o compromisso fordista significa a aceitação pelo proletariado da dominação pelo capital em troca de sua legitimidade e garantia da realização de seus interesses imediatos. (BIHR, 1998, p. 38)

${ }^{19}$ Expressão (traduzida do francês) usada por Bernard Edelman em sua obra de mesmo título.
} 
Ocorre que, no Brasil, o compromisso fordista não se deu diretamente entre os membros das próprias classes, mas institucionalmente. O governo de Getúlio Vargas institucionalizou o movimento operário e sindical, colocando-o como uma agência de natureza pública e exigindo a não transgressão da legalidade que lhe foi imposta. (VIANNA, 1999, p. 67)

Consolidaram-se todas as premissas corporativas instituídas até então. O Estado, ao legalizara classe trabalhadora, tratou de calá-la: por um lado, concedeu direitos, mas, por outro, cuidou de impedir a continuidade das lutas operárias e a própria existência do sentimento de classe (ou seja, minguou a esfera justrabalhista coletiva). O privilégio conferido pela CLT aos direitos trabalhistas individuais acabou implicando a divisão da classe trabalhadora e o seu controle pelas empresas e pelo Estado.

A legislação trabalhista, nos moldes em que restou estabelecida, significou ainda o despertar de uma disputa psicológica entre os próprios trabalhadores e a indução ao enfraquecimento do sindicalismo. Isso porque se propagou a ideia de que os sindicatos não mais se faziam necessários para a construção do Direito do Trabalho (os direitos trabalhistas seriam uma benesse estatal).

Assim, na intenção de se impedir qualquer ação sindical sem o controle do Estado, foram consolidados a unicidade sindical, o imposto sindical, o sistema confederativo hierarquizado, a investidura sindical (reconhecimento por parte do Ministério do Trabalho), o critério de agregação por categorias vinculado a ummolde oficial de enquadramento, o poder normativo da Justiça do Trabalho (prerrogativa de controle judicial dos movimentos reivindicatórios) e a data-base (negociações e tratativas coletivas anuais com data certa). $\mathrm{O}$ alicerce da união da classe trabalhadora estaria, pelo menos por muitas décadas, essencialmente esfacelado.

A legislação do trabalho no Brasil foi fruto, sim, de violenta luta, mas é possível afirmar que a classe trabalhadora foi desencaminhada dos seus propósitos pela legalização e pelo controle das suas organizações. A classe trabalhadora foi conduzida a um processo de integração ao capital, e os sindicatos foram transformados de agentes sociais a agentes jurídicos. Nesse sentido explica Bernard Edelman: 
Portanto, quando digo que "tudo" está ali para desviar a luta de classes, quero dizer, por exemplo, que as lutas operárias estão, elas mesmas, enclausuradas nesses aparelhos, elas se desenvolvem nessas estruturas e essas estruturas provocam efeitos sobre o combate da classe operária. É por isso que, se nos limitarmos a compreender o movimento operário por suas "conquistas” legais, não há dúvida de que faremos, então, a "história jurídica" e, desse modo, reproduziremos o ponto de vista da burguesia. (EDELMAN, 2016, p. 19)

O autor constrói o argumento de legalização a partir da incorporação normativa dos permanentes ajustes entre capital e trabalho (fator histórico do movimento operário), o que permitiu a transformação da relação capital/trabalho em relação jurídica (por isso, história jurídica). O Estado, assim, por meio dessa apropriação, decompôs o vínculo histórico da classe operária e transfigurou a concepção do Direito do Trabalho em "um direito burguês que se ajusta ao trabalho" (EDELMAN, 2016, p. 19):

[...] se por um lado podemos nos orgulhar do "poder" jurídico que a classe operária conquistou, por outro podemos perguntar de que natureza é esse poder, visto que é jurídico. Dito de outro modo, se a lei (burguesa) dá "poder" à classe operária, de que poder exatamente se trata? (EDELMAN, 2016, p. 19)

A lógica do Estado era a de estruturar o passado de lutas trabalhistas sem, no entanto, mencioná-lo. Esse suposto "novo modelo" de legislação promoveu, diante do discurso estatal, a desconexão entre as lutas de classe e a normatização trabalhista. Os direitos trabalhistas passaram a ser encarados como dádivas, desvinculados, assim, de sua verdadeira fonte:

O projeto estatal que constitui a identidade coletiva da classe trabalhadora articulou uma lógica material, fundada nos benefícios da legislação social, com uma lógica simbólica, que representava estes benefícios como doações e beneficiava-se da experiência de luta dos próprios trabalhadores. (GOMES, 1988, p. 254)

Percebe-se, portanto, que os fundamentos históricos do Direito do Trabalho brasileiro, em essência, decorrem da atuação coletiva dos trabalhadores, por meio de lutas e manifestações no início do século XX. A legalização das conquistas sociais, porém, foi propagandeada de modo a desvinculá-las de suas origens autônomas - benesses estatais, portanto -, como forma de controle e dominação da classe, pacificando as relações industriais e evitando a disseminação de conflitos sociais.

Trata-se do denominado mito da outorga que se contrapõe à verdadeira história da construção autônoma da legislação trabalhista por meio das manifestações coletivas da classe 
trabalhadora. Evaristo de Moraes Filho, questionando essa falácia atribuída ao Direito do Trabalho no Brasil, destaca que as iniciativas legislativas e os movimentos sociais grevistas deflagrados até a década de 1930 comprovam ser uma verdadeira injustiça e um equívoco histórico a atribuição de dádiva estatal à legislação social brasileira. (MORAES FILHO, 1978, p. 125-150)

A realização dessa utopia brasileira deu-se com base no direito social, permitindo o desenvolvimento de uma sociabilidade inerte, que, a partir da ruptura varguista, sobrevalorizou a mais das efêmeras melhorias (ou seja, o horizonte de expectativa desejável transmutou-se em um minimalismo jurídico). (CARDOSO, 2010, p. 418) ${ }^{20}$

Por isso se afirma que a consolidação legislativa de um Direito do Trabalho no Brasil foi fruto de uma equação complexa, considerando não apenas as lutas dos trabalhadores e suas conquistas, mas também a transição para uma economia industrializada, a transição para o trabalho livre e a transição do Estado Liberal para o Social (ou, pelo menos, tendências que se implantavam a partir da influência da superação do liberalismo nos países europeus).

Nessa perspectiva, portanto, pode-se afirmar que o modelo corporativo instaurado a partir da década de 1930 trouxe para a classe trabalhadora não só a sua conformação com o Estado capitalista ${ }^{21}$, mas, também, a perda de sua identidade histórica.

\section{CONSIDERAÇÕES FINAIS}

Em virtude das peculiaridades econômicas e sociais do Brasil - de formação colonial e cuja economia, eminentemente agrícola, se fundava na escravidão - e diante da política de

\footnotetext{
${ }^{20}$ Segundo o mesmo autor, cinco impactos foram decisivos para a construção da ordem capitalista e, por consequência, da sociabilidade brasileira: a opção paulista pelos imigrantes, o que formou uma querela legislativa entre posições contrárias e favoráveis à mão de obra alienígena; a degradação do trabalho manual pela escravidão, o que condicionou a ideia de trabalho a uma prática forçada; a existência de um padrão de violência estatal e privada, mantida mesmo após o fim da escravidão, aliada ao fraco aparato estatal para a repreensão do trabalho escravo; e a sobrevivência, nas relações trabalhistas no início da industrialização, de uma percepção do trabalhador brasileiro como pacífico. (CARDOSO, 2010, p. 62-70). Isso parece explicar como a ideologia da expectativa se enraizou na sociedade brasileira, fazendo com que a ideia de vitória fosse priorizada em detrimento à conquista propriamente.

21 “[...] a preservação da ordem impunha a necessidade de se integrarem as classes a fim de evitar o acirramento da luta de interesses que era capaz de convulsionar a sociedade. A ameaça de uma luta irrefreável e desagregadora entre trabalho e capital era, então, o fato impulsionador da elaboração da legislação social. Proteger e garantir condições dignas de trabalho ao proletariado era assegurar a ordem capitalista". (SUPERTI, 2004, p. 198-199)
}

\section{Revista de Pesquisa e Educação Jurídica | e-ISSN: 2525-9636| Maranhão | v. 3 | n. 2 |} p. 1 - 21 | Jul/Dez. 2017. 
estímulo à industrialização alicerçada por Getúlio Vargas, as décadas de 1930 e 1940 mostraram-se produtivas do ponto de vista da legislação heterônoma estatal.

Porém, conforme retratado, isso não significa que a legislação trabalhista foi integralmente concebida naquela fase. Pelo contrário, o Direito do Trabalho já se formatava no início do século XX, a partir de significativos movimentos sociais (ainda que sem uma estrutura jurídica específica) que, de forma autônoma, produziram grande parte da legislação que, porteriormente, restou consolidada pelo Estado.

O corporativismo, em razão da pulverização da classe trabalhadora e do definhamento do papel de transformação social dos sindicatos, foi responsável por essa desconexão entre o destinatário da norma e o seu criador, erigindo o denominado mito de outorga estatal. Ademais, percebeu-se ainda que a cooptação e a integração dos sindicatos ao Estado - controlando-lhes e retirando-lhes a liberdade intrínseca de organização - significou, também, a perda de identidade da própria classe trabalhadora.

Os efeitos dessa dupla desconexão - de identidade legislativa e de identidade de classe - ainda hoje podem ser percebidos. Apesar da promulgação de uma Constituição democrática em 1988 e do estabelecimento de um novo paradigma de Estado, os movimentos coletivos sindicais encontram-se enfraquecidos e a classe trabalhadora brasileira se queda inerte diante das falácias preconizadas pelo atual governo que, a pretexto da crise políticoeconômica, conseguiu concluir, sem qualquer subsídio popular, seu projeto neoliberal de reforma trabalhista - Lei n. 13.429, de 31 de março de 2017 e Lei n. 13.467, de 13 de julho de 2017.

\section{REFERÊNCIAS}

AQUINO, Rubim Santos Leão de [et al]. Sociedade brasileira: uma história através dos movimentos sociais - da crise do escravismo ao apogeu do neoliberalismo. São Paulo: Record, 2000.

BIAVASCHI, Magda Barros. O direito do trabalho no Brasil 1930-1942: a construção do sujeito de direitos trabalhistas. São Paulo: LTr, 2007.

BIHR, Alain. Da grande noite à alternativa: o movimento operário europeu em crise. Tradução de Wanda Caldeira Brant. São Paulo: Boitempo, 1998. 
BOBBIO, Norberto. O futuro da democracia. Trad. Marco Aurélio Nogueira. 8. ed. São Paulo: Paz e Terra, 2002.

BRASIL. Decreto do Poder Legislativo n. 979, de 6 de janeiro de 1903. Faculta aos profissionais da agricultura e industrias ruraes a organização de syndicatos para defesa de seus interesses. Imprensa Nacional, Rio de Janeiro, 8 jan. 1903. Disponível em: <http://www2.camara.leg.br/legin/fed/decret/1900-1909/decreto-979-6-janeiro-1903-584238publicacaooriginal-107004-pl.html>. Acesso em: 18 jul. 2017.

BRASIL. Decreto n. 6.532, de 29 de junho de 1907. Aprova o regulamento para a execução do decreto legislativo n. 979, de 6 de janeiro de 1903. Imprensa Nacional, Rio de Janeiro, 5 fev. 1908. Disponível em: <http://www2.camara.leg.br/legin/fed/decret/1900-1909/decreto6532-29-junho-1907-517583-publicacaooriginal-1-pe.html>. Acesso em: 18 jul. 2017.

BRASIL. Decreto n. 19.770, de 19 de março de 1931. Regula a sindicalização das classes patronais e operárias e dá outras providências. Imprensa Nacional, Rio de Janeiro, 29 mar. 1931. Disponível em: <http://www2.camara.leg.br/legin/fed/decret/1930-1939/decreto19770-19-marco-1931-526722-publicacaooriginal-1-pe.html>. Acesso em: 18 jul. 2017.

BRASIL. Constituição dos Estados Unidos do Brasil, de 10 de novembro de 1937. Imprensa Nacional, Rio de Janeiro, 10 nov. 1937. Disponível em:

<http://www.planalto.gov.br/ccivil_03/Constituicao/Constituicao37.htm>. Acesso em: 18 jul. 2017.

CARDOSO, Adalberto Moreira. A construção da sociedade do trabalho no Brasil: uma investigação sobre a persistência secular das desigualdades. Rio de Janeiro: Editora FGV, 2010 .

COUTINHO, Aldacy Rachid. Trajetória do sindicalismo brasileiro: análise do suporte legislativo. In: ARAÚJO, Silvia Maria de; FERRAZ, Marcos.Trabalho e sindicalismo: tempo de incertezas. São Paulo: LTr, 2006.

DELGADO, Mauricio Godinho. Curso de direito do trabalho. 15. ed. São Paulo: LTr, 2016.

EÇA, Vitor Salino de Moura; LOBATO, Marcia Regina. Atualização da ação sindical para os desafios da contemporaneidade. Revista de Movimentos Sociais e Conflitos, Minas Gerais, v. 1, n. 2, p. 129-154, jul./dez. 2015.

EDELMAN, Bernard. A legalização da classe operária.Tradução de Marcus Orione [Coord.]. 1. ed. São Paulo: Boitempo, 2016.

FAUSTO, Boris. História do Brasil. São Paulo: Edusp, 2006.

FRENCH, John D. Afogados em leis: a CLT e a cultura política dos trabalhadores brasileiros. São Paulo: Fundação Perseu Abramo, 2001. 
GOMES, Ângela Maria de Castro. A invenção do trabalhismo. São Paulo: Vértice, 1988.

LOBO, Valéria Marques. Desmercantilização do trabalho da perspectiva do movimento sindical (Brasil, 1950-2000). DADOS - Revista de Ciências Sociais, Rio de Janeiro, v. 52, n.1, p. 85-121, 2009.

MAGANO, Otávio Bueno. Manual de direito do trabalho. São Paulo: LTr, 1993.

MORAES FILHO, Evaristo de. O problema do sindicato único no Brasil. São Paulo: Alfa Ômega, 1978.

QUINALHA, Renan Honório. O modelo legislado de relações de trabalho brasileiro: uma classificação para além do corporativismo. Revista LTr, São Paulo, v. 76, n. 03, p. 328-335, mar/ 2012.

RAMALHO, Maria do Rosario Palma. Tratado de direito do trabalho parte III: situações laborais colectivas. 2. ed. Coimbra: Almedina, 2015.

ROMITA, Arion Sayão. O direito sindical brasileiro, segundo José Martins Catharino.

Revista de Direito do Trabalho. São Paulo, v. 54, p. 30-46, mar./abr. 1985.

ROMITA, Arion Sayão. $\mathbf{O}$ fascismo no direito do trabalho brasileiro: influência da carta del lavoro sobre a legislação trabalhista brasileira. São Paulo: LTr, 2001.

SILVA, Sayonara Grillo Coutinho Leonardo da. Relações coletivas de trabalho: configurações institucionais no Brasil contemporâneo. São Paulo: LTr, 2008.

SUPERTI, Eliane. Da incorporação do proletariado ao direito do trabalho: um estudo sobre o projeto positivista de organização das relações de trabalho no Brasil. 2004. $232 \mathrm{f}$. Tese (Doutorado) - Universidade Federal de São Carlos, Departamento de Pós-Graduação em Ciências Sociais, São Carlos, 2004.

SÜSSEKIND, Arnaldo. Direito constitucional do trabalho. 2. ed. Rio de Janeiro: Renovar, 2001.

SÜSSEKIND, Arnaldo [et al.]. Instituições de direito do trabalho. 21. ed. São Paulo: LTr, 2003.

TELLES, Jover. O movimento sindical no Brasil. 2. ed. São Paulo: Livraria Editora Ciências Humanas, 1981.

VARGAS, Getúlio. A nova política do Brasil. Rio de Janeiro: José Olympio, 1938, v. 1.

VIANNA, Luiz Werneck. Liberalismo e sindicato no Brasil. 4. ed. Belo Horizonte: UFMG, 1999. 